\title{
THE EFFECT OF PHARMACEUTICAL INNOVATION ON LONGEVITY: \\ PATIENT-LEVEL EVIDENCE FROM THE 1996-2002 MEDICAL EXPENDITURE PANEL SURVEY AND LINKED MORTALITY PUBLIC-USE FILES
}

\author{
Frank R. Lichtenberg \\ Working Paper 18552 \\ http://www.nber.org/papers/w18552
NATIONAL BUREAU OF ECONOMIC RESEARCH
1050 Massachusetts Avenue
Cambridge, MA 02138
November 2012

This research was supported by the American Enterprise Institute, Novartis, and Pfizer. The sponsors placed no restrictions or limitations on data, methods, or conclusions, and had no right of review or control over the outcome of the research. The views expressed herein are those of the author and do not necessarily reflect the views of the National Bureau of Economic Research.

NBER working papers are circulated for discussion and comment purposes. They have not been peerreviewed or been subject to the review by the NBER Board of Directors that accompanies official NBER publications.

(C) 2012 by Frank R. Lichtenberg. All rights reserved. Short sections of text, not to exceed two paragraphs, may be quoted without explicit permission provided that full credit, including $(\mathbb{C}$ notice, is given to the source. 
The Effect of Pharmaceutical Innovation on Longevity: Patient-Level Evidence from the 1996-2002 Medical Expenditure Panel Survey and Linked Mortality Public-Use Files

Frank R. Lichtenberg

NBER Working Paper No. 18552

November 2012

JEL No. I12,J11,O33

\begin{abstract}
We investigate the effect of the vintage (year of FDA approval) of the prescription drugs used by an individual on his or her survival and medical expenditure. When we only control for age, sex, and interview year, we estimate that a one-year increase in drug vintage increases life expectancy by $0.52 \%$. Controlling for other variables including activity limitations, race, education, family income as a percent of the poverty line, insurance coverage, Census region, BMI, smoking and over 100 medical conditions has virtually no effect on the estimate of the effect of drug vintage on life expectancy.

Between 1996 and 2003, the mean vintage of prescription drugs increased by 6.6 years. This is estimated to have increased life expectancy of elderly Americans by $0.41-0.47$ years. This suggests that not less than two-thirds of the 0.6-year increase in the life expectancy of elderly Americans during 1996-2003 was due to the increase in drug vintage. The 1996-2003 increase in drug vintage is also estimated to have increased annual drug expenditure per elderly American by $\$ 207$, and annual total medical expenditure per elderly American by $\$ 218$. This implies that the incremental cost-effectiveness ratio (cost per life-year gained) of pharmaceutical innovation was about $\$ 12,900$.
\end{abstract}

Frank R. Lichtenberg

Columbia University

504 Uris Hall

3022 Broadway

New York, NY 10027

and NBER

frl1@columbia.edu 
Longevity increase is increasingly recognized by economists to be an important part of economic growth and development. ${ }^{1}$ Economists have also recognized for many years that, in the long run, economic "growth...is driven by technological change that arises from intentional [research and development (R\&D)] investment decisions made by profit-maximizing agents” (Romer (1990)) and by public organizations such as the National Institutes of Health. In principle, technological change could be either disembodied or embodied in new goods. Solow (1960) hypothesized that most technological change is embodied: to benefit from technological progress, one must use newer, or later vintage, ${ }^{2}$ goods and services. Bresnahan and Gordon (1996) argued that "new goods are at the heart of economic progress," and Hercowitz (1998, p. 223) also reached the "conclusion...that 'embodiment' is the main transmission mechanism of technological progress to economic growth."

In this paper, I will use patient-level data to analyze the effect of technological change embodied in pharmaceuticals on the longevity of elderly Americans. ${ }^{3}$ The basic approach will be to investigate whether patients using newer drugs in a given year remain alive longer than patients using older drugs, controlling for many important patient characteristics.

Two previous studies have examined the effect of pharmaceutical innovation on longevity using patient-level data. Lichtenberg et al (2009) analyzed medical and pharmacy claims data on elderly patients enrolled in Quebec's provincial health plan (Régie de l'assurance maladie du Québec), during the period 1997-2006. Lichtenberg (2010) analyzed medical and pharmacy claims data from Puerto Rico’s Medicaid program during the period 2000-2002. Both studies found that the use of newer medications was associated with a statistically significant mortality risk reduction, relative to older medications.

While these two studies were useful, they were subject to several limitations. First, they controlled for some important patient characteristics, such as age, sex, region, and the presence of various medical conditions, but, since they were based entirely on administrative data, they were unable to control for other characteristics, such as education, income, and race. Second, both studies provided estimates of the effect of using newer drugs on the probability of surviving

\footnotetext{
${ }^{1}$ See e.g. Nordhaus (2002) and Murphy and Topel (2005).

${ }^{2}$ According to the Merriam Webster dictionary, one definition of vintage is "a period of origin or manufacture (e.g. a piano of 1845 vintage)". http://www.merriam-webster.com/dictionary/vintage

${ }_{3}^{3}$ According to the National Science Foundation, the pharmaceutical and medical devices industries are the most research intensive industries in the economy.
} 
a certain period of time, ${ }^{4}$ but neither provided estimates of the effect of using newer drugs on mean time till death (life expectancy), or of the overall cost-effectiveness of new drugs relative to old drugs. And third, neither study was based on nationally representative samples of individuals.

The present study will overcome these limitations. The data we will use (primarily derived from the Medical Expenditure Panel Survey and the Linked Mortality Public-use Files) will enable us to control for a larger set of potentially important patient characteristics. We will show that controlling for these characteristics has virtually no effect on the estimate of the effect of drug vintage on life expectancy, because drug vintage is not correlated with several important individual attributes, including insurance coverage, race, and family income as a percent of the poverty line. We will provide estimates (which we believe to be quite robust and reliable) of the effect of using newer drugs on life expectancy per se, as well as its effect on pharmaceutical and overall medical expenditure. Hence, we can estimate the incremental cost-effectiveness (cost per life-year gained) of using newer drugs. These estimates will be based on a nationally representative sample of elderly U.S. community residents. ${ }^{5}$

Several previous studies (e.g. Lichtenberg and Duflos (2008), Lichtenberg (2011, 2012)) have examined the effect of pharmaceutical innovation on longevity and medical expenditure using aggregate (longitudinal state-level or disease-level) data from the U.S. and other countries. We will compare the estimates we obtain from our patient-level sample to estimates obtained from previous analyses of aggregate data.

\section{General approach}

Figure 1 illustrates the general approach we will use. We will investigate the effect of the vintage of the prescription drugs used by an individual on his or her survival and medical expenditure, controlling for a number of demographic characteristics and indicators and determinants of health status. We will do this by estimating models of the following general form:

$$
\text { survival }_{\mathrm{i}}=\beta \text { rx_vintage } \mathrm{i}_{\mathrm{i}}+\gamma \mathrm{Z}_{\mathrm{i}}+\varepsilon_{\mathrm{i}}
$$

\footnotetext{
${ }^{4}$ Lichtenberg (2010) examined whether Puerto Rico Medicaid beneficiaries using newer drugs during January- June 2000 were less likely to die by the end of 2002, conditional on the covariates.

${ }^{5}$ Nursing home residents, which account for about $4 \%$ of the elderly population (http://www.cdc.gov/nchs/data/hus/hus09.pdf\#105), are not included in our sample.
} 
where

$$
\begin{aligned}
\text { survival }_{\mathrm{i}} & =\text { a measure based on individual i’s survival time (number of years } \\
& \text { until death) } \\
\text { vintage }_{\mathrm{i}} & =\text { a measure of the vintage of prescription drugs used by individual i } \\
\mathrm{Z}_{\mathrm{i}} & =\text { a vector of other attributes of individual i } \\
\varepsilon_{\mathrm{i}} & =\text { a disturbance }
\end{aligned}
$$

First, I will discuss the measures of survival and appropriate estimation methods. Then I will discuss the measurement of drug vintage. Third, I will describe the other individual attributes I will control for. Fourth, I will consider why there is likely to be substantial variation in drug vintage, even controlling for all of these attributes. In order for estimates of $\beta$ to identify the effect of pharmaceutical innovation on longevity, there must be a large random component in the assignment of drugs to individuals. A substantial body of literature indicates that this is the case.

\section{A. Measures of survival and appropriate estimation methods}

Most of the data we will use were obtained from the 1996-2002 waves of the Medical Expenditure Panel Survey (MEPS), a set of large-scale surveys of families and individuals, their medical providers, and employers across the United States. MEPS is the most complete source of data on the cost and use of health care and health insurance coverage. The Household Component (HC) of MEPS provides data from individual households and their members, which is supplemented by data from their medical providers. It collects data from a sample of families and individuals in selected communities across the United States, drawn from a nationally representative subsample of households that participated in the prior year's National Health Interview Survey (conducted by the National Center for Health Statistics). During the household interviews, MEPS collects detailed information for each person in the household on the following: demographic characteristics, health conditions, health status, use of medical services, charges and source of payments, access to care, satisfaction with care, health insurance coverage, income, and employment. For example, MEPS provides data about (including the 11-digit National Drug Codes of) all of the prescription drugs used by a patient during a calendar year. The MEPS is a panel study, but I will use it as a cross section: each individual will contribute a single observation to the sample, using data from the first year the person was included in the survey. 
I am able to track a patient's vital status for up to 10 years after he or she was in the MEPS sample because (1) the set of households selected for each panel of the MEPS HC is a subsample of households participating in the previous year's National Health Interview Survey (NHIS) conducted by the National Center for Health Statistics, ${ }^{6}$ and (2) the NHIS Linked Mortality Public-use Files provide mortality follow-up data for the NHIS years 1986-2004 from the date of interview through December 31, 2006. ${ }^{7}$ Let

interview_date $_{\mathrm{i}}=$ the date individual $\mathrm{i}$ was interviewed death_date $_{\mathrm{i}}=$ the date individual $\mathrm{i}$ died surv_time $_{i}=$ death_date $_{i}-$ interview_date $_{i}=$ the number of years individual $\mathrm{i}$ survived after being interviewed

If individual i did not die by December 31, 2006, his or her death date is unknown-we only know that the death date was or will be after December 31, 2006. Hence, the variable surv_time is right-censored. We will estimate versions of eq. (1), in which the dependent variable is surv_time, using a statistical procedure (the SAS LIFEREG procedure) that fits parametric models to failure time data that can be uncensored, right censored, left censored, or interval censored. I will assume that the number of years the patient lived after being interviewed (or the number of years till death) has the Weibull distribution, one of the most commonly used distributions in failure time analysis. The probability density function of a Weibull random variable $X$ is:

$$
f(x ; \lambda, k)= \begin{cases}\frac{k}{\lambda}\left(\frac{x}{\lambda}\right)^{B-1} e^{-\left(x / x y^{2}\right.} & x \geq 0, \\ 0 & x<0,\end{cases}
$$

where $k>0$ is the shape parameter and $\lambda>0$ is the scale parameter of the distribution. ${ }^{8}$ The mean of a Weibull random variable can be expressed as $\lambda \Gamma(1+(1 / \mathrm{k}))$ where $\Gamma(\mathrm{z})$ is the Gamma function: ${ }^{9}$

\footnotetext{
${ }^{6}$ NHIS/MEPS Public Use Person Record Linkage files contain crosswalks that allows data users to merge MEPS full-year public use data files to NHIS person-level public use data files that contain data collected for MEPS respondents in the year prior to their initial year of MEPS participation; see http://www.meps.ahrq.gov/mepsweb/data_stats/more_info_download_data_files.jsp\#hc-nhis ${ }^{7}$ http://www.cdc.gov/nchs/data_access/data_linkage/mortality/nhis_linkage_public use.htm

8 The shape parameter is what gives the Weibull distribution its flexibility. By changing the value of the shape parameter, the Weibull distribution can model a wide variety of data. If $\mathrm{k}=1$, the Weibull distribution is identical to the exponential distribution; if $\mathrm{k}=2$, the Weibull distribution is identical to the Rayleigh distribution; if $\mathrm{k}$ is between 3 and 4 the Weibull distribution approximates the normal distribution. The Weibull distribution approximates the lognormal distribution for several values of $k$.

${ }^{9}$ See http://en.wikipedia.org/wiki/Weibull_distribution and http://www.engineeredsoftware.com/nasa/weibull.htm.
} 


\section{$\Gamma(x)=\int_{0}^{\infty} t^{x-1} e^{-t} \mathrm{~d} t$}

We assume that the scale parameter $\lambda$ depends on patient characteristics $X$ as follows: $\lambda=$ $\exp (\beta X)$. Hence $\ln \lambda=\beta X$, and $\ln ($ mean survival time $)=\beta X+\ln (\Gamma(1+(1 / k)))$. Therefore the estimated coefficient on a patient characteristic $\mathrm{X}_{1}$ indicates the percentage change in mean survival time attributable to a unit increase in $\mathrm{X}_{1}$.

Our estimation procedure allows us to use right-censored survival data, but the precision of our estimates will be greater, the larger the fraction of the observations that are not censored. To increase the precision of the estimates, I will analyze people 65 years and older ("the elderly”) who were interviewed during 1996-2000. The five-year mortality rate of elderly people is over nine times as high as the five-year mortality rate of nonelderly people (23.3\% vs. $2.6 \%$ ). Choosing 2000 as the final sample year ensures that each individual's vital status can be tracked for a minimum of six years. The survival times of $38 \%$ of the people 65 years and older who were interviewed during 1996-2000 are not censored.

Unfortunately, MEPS did not obtain data on two potentially important behavioral risk factors prior to 2000: data on whether or not the individual currently smokes began in 2000, and data on body mass index began in 2001. ${ }^{10}$ Therefore, including these variables in the surv_time model is not feasible. However, we can assess whether controlling for these variables affects our estimates of the effect of pharmaceutical innovation on survival by using an alternative measure of survival:

$$
\begin{aligned}
\text { surv_3_year }_{i} & =1 \text { if surv_time } \\
& =0 \text { if surv_time } \\
& <3 \text { years } \\
& =3 \text { years }
\end{aligned}
$$

When the dependent variable of eq. (1) is defined as surv_3_year, the model including the two behavioral risk factors can be estimated using data on people interviewed in 2001 and 2002. Since the dependent variable is binary, we will estimate this model as a probit model.

\footnotetext{
${ }^{10} \mathrm{CDC}$ (2005) provides estimates of smoking-attributable mortality; Flegal et al (2005) provides estimates of the effects of obesity on U.S. mortality.
} 


\section{B. Measurement of drug vintage}

MEPS Prescribed Medicines files provide data on all outpatient prescription drugs used by each individual. ${ }^{11}$ We identified the active ingredients of all of the medications used by each respondent. We used data provided by the FDA (http://www.fda.gov/Drugs/InformationOnDrugs/ucm079750.htm) to determine the year in which the FDA first approved a product containing that active ingredient. From the Drugs@FDA database, we constructed the following variables:

ingred_year $\mathrm{a}_{\mathrm{a}}=$ the year in which the FDA first approved a product containing active ingredient a $(\mathrm{a}=1, \ldots, 800)$

$\operatorname{post}_{1975}=1$ if ingred_year $>1975$

$=0$ otherwise

post1985 $_{\mathrm{a}}=1$ if ingred_year $\mathrm{a}>1985$

$=0$ otherwise

MEPS provides data on $n_{-} \mathrm{rx}_{\mathrm{ia}}$ : the total number of medications used by individual $\mathrm{i}$ that contained active ingredient a. We combined the MEPS medication data with the FDA ingredient attribute data to construct the following variables characterizing the distribution of medications used by each individual:

rx_year ${ }_{i}=\left(\Sigma_{\mathrm{a}} \mathrm{n} \_r x_{i a}\right.$ ingred_year $\left.a\right) / \Sigma_{\mathrm{a}} \mathrm{n} \_r x_{i a}=$ the (weighted) mean vintage of medications used by individual $\mathrm{i}$

rx_post1975\% $\%_{\mathrm{i}}=\left(\Sigma_{\mathrm{a}} \mathrm{n} \_\mathrm{rx}_{\mathrm{ia}}\right.$ post1975 $) / \Sigma_{\mathrm{a}} \mathrm{n} \_\mathrm{rx}$ ia $=$ the fraction of medications used by individual $\mathrm{i}$ that contained active ingredients approved after 1975

rx_post $1985 \%$ i $=\left(\Sigma_{\mathrm{a}} \mathrm{n} \_\mathrm{rX}_{\mathrm{ia}}\right.$ post1985 $) / \Sigma_{\mathrm{a}} \mathrm{n} \_\mathrm{rX}$ ia $=$ the fraction of medications used by individual $\mathrm{i}$ that contained active ingredients approved after 1985

\section{Other individual attributes}

The survival models we estimate will include an extensive set of demographic characteristics and indicators and determinants of health status. The effects of some of these variables on mortality and survival are well documented. For example, life tables published by the CDC (Arias et al (2008)) show how life expectancy depends on age, sex, and race. The life table figures can be used as a benchmark against which we can compare our estimates.

\footnotetext{
${ }^{11}$ MEPS does not provide information about provider-administered drugs, e.g. chemotherapy. Provideradministered drugs may account for about $15 \%$ of total U.S. drug expenditure.
} 
A person’s life expectancy also clearly depends on the medical conditions a person has. For example, during 2001-2007, the 5-year relative survival rate of a person with breast cancer was $89.1 \%$, whereas the 5 -year relative survival rate of a person with pancreatic cancer was only $5.5 \%{ }^{12}$ We will control for the presence or absence of over 100 (2-digit ICD9) medical conditions by including a dummy variable for each condition. ${ }^{13}$ There are 4 possible reasons why a person could be defined as having a given medical condition: (1) the person responded affirmatively when specifically asked whether he or she has ever been diagnosed with the condition; (2) the condition was reported by the person as the reason for a particular medical event (hospital stay, outpatient visit, emergency room visit, home health episode, prescribed medication purchase, or medical provider visit); (3) the condition was reported as the reason for one or more episodes of disability days; and (4) the condition was reported by the person as a condition "bothering" the person during the reference period. ${ }^{14}$

A person's life expectancy may depend not just on whether he or she has a medical condition, but on how long he or she has had the condition. MEPS Medical Conditions files provide some information on the duration of medical conditions (i.e. the date the condition began), but this information is very incomplete. However, MEPS Prescribed Medicines files provide fairly complete information on the date the person started taking each medicine. Mean duration of medication use (or the mean year the person started taking his or her medications (began_med_year)) may serve as a reasonable proxy for mean duration of medical condition. We will include began_med_year as an explanatory variable.

In addition to data on medical conditions and their treatment, MEPS provides data on the functional status and activity limitations of individuals. In particular, MEPS respondents are asked whether or not they experience any limitation in work, housework, or school activities, and if so, whether they are completely unable to perform those activities. We constructed the following measure of activity limitations:

act_lim ${ }_{\mathrm{i}}=2$ if person i was completely unable to work at a job, do housework, or go to school $=1$ if person i was limited in these activities but not completely unable to perform them $=0$ if person i was not limited in these activities

\footnotetext{
${ }^{12}$ SEER Cancer Statistics Review, 1975-2008, http://seer.cancer.gov/csr/1975_2008/results_merged/topic_survival.pdf

${ }^{13}$ The dummy variables were constructed using data in the MEPS Medical Conditions files.

${ }^{14}$ In some previous studies based on claims data, a person would be considered to have a medical condition only if the diagnosis code for that condition appeared in a medical claim.
} 
One would expect that people whose activities are more limited have lower life expectancy, ceteris paribus. However, if pharmaceutical innovation improves health (and reduces activity limitations), then estimates of $\beta$ in eq. (1) — the effect of drug vintage on life expectancy —are likely to be conservative when $\mathrm{Z}$ includes act_lim. We will present estimates of eq. (1) both excluding and including act_lim.

We also include two measures of socioeconomic status - income and education-in the survival model. Many studies have found a positive correlation between these variables and life expectancy. However, cross-sectional correlations between longevity and either income or education may substantially overestimate the effect of socioeconomic status per se on longevity. For example, the positive correlation between income and longevity may reflect the effect of health on income ("reverse causality") as well as the effect of income on health. Almond and Mazumder (2006) argue that, “although it is well known that there is a strong association between education and health, much less is known about how these factors are connected, and whether the relationship is causal.”15

\section{Why does drug vintage vary, controlling for these individual attributes?}

We believe that heterogeneous pharmaceutical treatment of patients, controlling for their medical conditions, demographic characteristics, insurance coverage, and other factors, is primarily due to physician practice variation. Wennberg (2004) argues that "unwarranted [treatment] variation — variation not explained by illness, patient preference, or the dictates of evidence-based medicine-is a ubiquitous feature of U.S. health care.” A large number of studies have documented the importance of unexplained variation in medical care in general and prescribing behavior in particular. Wennberg and Wennberg examined variation in nine drugs or classes of drugs among members of Blue Cross and Blue Shield of Michigan, and argued that “evidence does not, per se, ensure that pharmaceuticals are always used rationally.” Lee et al

\footnotetext{
${ }^{15}$ Lleras-Muney (2005) provided perhaps the strongest evidence that education has a causal effect on health. Using state compulsory school laws as instruments, Lleras-Muney found large effects of education on mortality. Almond and Mazumder (2006) revisited these results, noting they were not robust to state time trends, even when the sample was vastly expanded and a coding error rectified. They employed a dataset containing a broad array of health outcomes and found that when using the same instruments, the pattern of effects for specific health conditions appeared to depart markedly from prominent theories of how education should affect health. They also found suggestive evidence that vaccination against smallpox for school age children may account for some of the improvement in health and its association with education. This raised concerns about using compulsory schooling laws to identify the causal effects of education on health.
} 
(2008) showed that "pediatric and adult transplant physicians differed significantly in their management strategies for chronic myeloid leukemia, acute and chronic graft-versus-host disease, and choice of graft source for patients with aplastic anemia. Among adult transplant physicians, there was little agreement on the patient factors favoring reduced intensity conditioning or myeloablative conditioning.” DeSalvo et al (2000) reported “wide variation...in assignment of reappointment interval with mean return intervals...ranging from 2.2 to 20.5 weeks. Sex was a significant provider independent variable...Female providers assigned earlier reappointment intervals for their patients.” Solomon et al (2003) found that "established risk factors for NSAID-associated gastrointestinal toxicity were poor predictors of who was prescribed a selective COX-2 inhibitor; in contrast, physician prescribing preference was an important determinant." De Las Cuevas et al (2002) showed that "there is a remarkable degree of variation in antidepressant prescribing by psychiatrists and general practitioners; this is due to economic and social factors as much as to morbidity differences.” Rochon et al (2007) found that "residents in facilities with high antipsychotic prescribing rates were about 3 times more likely than those in facilities with low prescribing rates to be dispensed an antipsychotic agent, irrespective of their clinical indication."16 Zink et al (2001) found that "trends in the drug management of [rheumatoid arthritis] are adopted differentially by the members of the rheumatology community.” Davis and Gribben (1995) found that “data from a survey of general practice in New Zealand confirm the existence of extensive variability in prescribing. Controlling for patient, diagnostic, and practitioner variables...does not reduce the extent of interpractitioner variability in prescribing rates.” Moreover, de Jong et al (2009) found that decision support systems do not reduce variation in prescribing.

We will assess the extent of prescribing practice variation in our sample of individuals by estimating the following equation:

$$
\text { rx_vintage } e_{i}=\pi Z_{i}+\varepsilon_{i}
$$

\footnotetext{
${ }^{16}$ Using clinical and administrative data obtained from all facilities in a Department of Veterans Affairs integrated service network, Krein et al (2002) showed that there was variation in diabetes practice patterns at the primary care provider, provider group, and facility levels, and that the greatest amount of variance tended to be attributable to the facility level.
} 
The $\mathrm{R}^{2}$ of this equation indicates the fraction of the variance in prescription drug vintage that is explained by variation in medical conditions and other individual attributes. A low $\mathrm{R}^{2}$ would be indicative of substantial practice variation.

\section{Descriptive statistics}

Now I will present some descriptive statistics. Following the sequence of the previous section, I will first present statistics about life expectancy. Next, I will present statistics about the vintage of prescription drugs. Third, I will present statistics about other patient attributes. Finally, I will present estimates of eq. (2), to assess the extent of prescribing practice variation in our sample.

Life expectancy. Our sample consists of people age 65 and over interviewed in the MEPS during 1996-2000 who were eligible for mortality follow-up ${ }^{17}$ and who had at least one prescription drug $^{18}$ during the interview year. Table 1 shows some sample statistics.

We estimated survival functions for both sexes combined and separately by sex using the right-censored surv_time observations, and no explanatory variables (only an intercept). This provided the estimates of the Weibull shape and scale parameters ( $k$ and $\lambda)$ and of mean survival time $(\lambda \Gamma(1+(1 / \mathrm{k}))$ shown in Table 2. Mean survival time computed from the right-censored surv_time observations is about 15\% higher than mean life expectancy based on the 1999-2001 CDC life table. We can think of two possible reasons for this. One is that CDC life-table estimates of life expectancy are based on nursing-home residents as well as community residents, whereas our sample only includes community residents, who are certainly healthier. A second, less important reason is that the CDC life table is a period life table, whereas the parameter estimates are, in effect, estimates of the cohort life table. ${ }^{19}$

\footnotetext{
${ }^{17}$ Less than half of MEPS respondents were eligible for mortality follow-up. See http://www.cdc.gov/nchs/data/datalinkage/nhis frequency_of_selected_variables_public_2010.pdf.

${ }^{18}$ In 2000, 88\% of elderly MEPS respondents had at least one prescription drug during the year.

${ }^{19}$ The Social Security Administration publishes both period and cohort U.S. life tables (http://www.ssa.gov/oact/NOTES/as120/LifeTables_Body.html). The estimate of life expectancy of 70-year-olds in 2000 from the (1930 birth) cohort life table is higher than the estimate of life expectancy of 70-year-olds in 2000 from the period life table, but only about $2 \%$ higher.
} 
The life-table and parametric estimates of the percentage differential between female and male life expectancy are quite similar: $13.5 \%$ and $11.5 \%$. Overall, our statistical procedure seems to yield plausible estimates of the survival distribution.

Drug vintage. Statistics describing the vintage of prescription drugs used by elderly MEPS respondents during the period 1996-2008 are shown in Table3. ${ }^{20}$ Not surprisingly, drug vintage increased over time. rx_post1975\% (the fraction of medications that contained active ingredients approved after 1975) increased from 57\% in 1996 to 75\% in 2008, and rx_post1985\% increased from 26\% in 1996 to 57\% in 2008. rx_year (the weighted mean FDA approval year) increased by 8 years during this period. ${ }^{21}$ However, the average annual rate of increase was three times as high from 1996 to 2003 as it was from 2003 to 2008 (0.9 vs. 0.3 years/year). The post-1995 decline in the number of new drugs approved by the FDA, illustrated in Figure 2, probably contributed to the decline in the rate of increase of drug vintage.

As shown in Table 4, there is considerable variation in drug vintage across individuals. The difference between the $75^{\text {th }}$ percentile and the $25^{\text {th }}$ percentile of the vintage distribution is 12.3 years (1983.0 vs. 1970.7 ); the difference between the $90^{\text {th }}$ percentile and the $10^{\text {th }}$ percentile of the vintage distribution is 24.8 years (1988.4 vs. 1963.6).

Other variables. Frequency distributions of many of the individual attributes shown in Figure 1 are presented in Table 5.

Prescribing practice variation. To assess the degree of unexplained variability in prescription drug use, we estimated eq. (2): a regression of rx_year on a large set of individual attributes: dummy variables for interview year, age, sex, race, marital status, Census region, insurance coverage, education, income (poverty group category), and presence of 100+ medical conditions. Table 6 shows the Type III (marginal) sums of squares for all factors except the medical conditions. Several factors (interview year, region, sex, and education) are statistically significant. The significance of interview year is not surprising, since we already saw in Table 3 that drug vintage tends to increase over time. The estimates in Table 6 indicate that drugs used in the western U.S. are about 2 years older than drugs used in the rest of the country; drugs used by women are about a year older than drugs used by men; and that highly educated people tend

\footnotetext{
${ }^{20}$ These statistics describe the vintage of prescription drugs used by all elderly MEPS respondents, including those not eligible for mortality follow-up.

${ }^{21}$ In 1996, the mean age (number of years since FDA approval) of drugs consumed was 20.1 years; in 2008, it was 24.1 years.
} 
to use newer drugs than less educated people. Drug vintage is not significantly related to several important individual attributes, including insurance coverage, race, and family income as a percent of the poverty line. The $\mathrm{R}^{2}$ of this regression is only $12 \%$, which indicates that only $1 / 8$ of the variation in drug vintage is explained by the presence of $100+$ medical conditions and key demographic and socioeconomic variables. This is consistent with the literature documenting substantial variation in prescribing and drug use.

\section{Empirical results}

Estimates of three versions of eq. (1) are shown in Table 7. In all three versions, the dependent variable is the right-censored variable surv_time (the number of years individual i survived after being interviewed), and the measure of drug vintage is rx_year (the (weighted) mean vintage of medications used by individual i). The three models differ in terms of the other attributes (Z) that are included. In model 1, the only other attributes included are dummy variables for age, sex, and interview year. Estimates of the coefficients on these variables seem reasonable: life expectancy declines with age, is higher for women than for men, and was lower in 1996-1997 than it was in 1998-2000. In this model, the rx_year coefficient $(\beta)$ is positive and highly significant (p-value $=.001)$; the point estimate $(.0056)$ indicates that a one-year increase in drug vintage increases life expectancy by $0.56 \%{ }^{22}$

Model 2 includes a much more extensive set of other attributes: began_med_year (the mean year the person started taking his or her medications, which may serve as a proxy for mean duration of medical conditions); race; education; family income as a percent of the poverty line; insurance coverage; Census region; marital status; and over 100 medical condition dummy variables. $^{23}$ The coefficient on began_med_year is not statistically significant. Also, the difference in life expectancy between people with and without private health insurance is not significant. Regional differences are also insignificant. The race coefficients indicate that the

\footnotetext{
${ }^{22}$ The absolute increase in life expectancy (LE) due to a one-year increase in drug vintage depends on mean life expectancy: since $\beta=\mathrm{d} \ln \mathrm{LE} / \mathrm{d}$ rx_year $=(1 / \mathrm{LE})$ * $(\mathrm{d} \mathrm{LE} / \mathrm{d}$ rx_year $), \mathrm{d}$ LE / $\mathrm{d}$ rx_year, $\mathrm{d}$ LE / d rx_year $=\beta$ * LE. As discussed above, we have two estimates of sample mean life expectancy: mean life expectancy based on the 1999-2001 CDC life table (11.9 years), and mean life expectancy (survival time) computed from the right-censored surv_time observations: (13.7 years). Below we will calculate the absolute increase in life expectancy and incremental cost effectiveness using each of these estimates of mean life expectancy.

${ }^{23}$ Coefficients on marital status and medical condition dummies are not shown to conserve space.
} 
life expectancy of blacks is $9 \%$ lower than that of whites (p-value $=.078)$, and that the life expectancy of Asians is 39\% higher than that of whites (p-value $=.022$, despite the fact that only $1.4 \%$ of sample members are Asians). The income and education group variables indicate that, overall, people in higher income categories and with more education have longer life expectancy. However, controlling for this much more extensive set of other attributes has virtually no effect on the point estimate of $\beta$. The difference between the estimates of $\beta$ in models 1 and 2 is not statistically significant. $^{24}$

Model 3 includes one additional individual attribute: act_lim, the index of activity limitations. We argued above that estimates of the effect of drug vintage on life expectancy are likely to be conservative when we control for act_lim. As one would expect, the life expectancy of people with activity limitations is lower than that of people without activity limitations. Controlling for activity limitations reduces the estimate of $\beta$, but only slightly $(\beta=.0052$, $\mathrm{p}$ value $=.003)$.

We also estimated two models (models 4 and 5) similar to model 3 in which we replaced the drug vintage measure rx_year by one of the alternative measures (rx_post1975\% or rx_post1985\%). The estimates of the drug vintage coefficients models 3, 4, and 5 are shown in Table 8. The coefficients in all three models are statistically significant (p-value $<.05$ ). Each of the models provides an estimate of how much the increase in drug vintage during a given period (e.g. 1996-2003) increased the life expectancy of elderly Americans. As shown in Table 3, during the period 1996-2003, rx_year increased by 6.6 years, rx_post1975\% increased by 14 percentage points, and rx_post1985\% increased by 26 percentage points. Therefore, model 3 implies that the increase in drug vintage during 1996-2003 increased the life expectancy of elderly Americans by 3.4\% (=.0052*6.6), model 4 implies that the increase in drug vintage increased their life expectancy by $2.5 \%(=.177 * 0.14)$, and model 3 implies that the increase in drug vintage increased their life expectancy by $2.9 \%(=.112 * 0.26)$. Since the choice of newdrug/old-drug threshold year (e.g. 1975 or 1985) is arbitrary, and rx_year (based on the continuous ingredient vintage measure rx_year) presumably conveys more information than the

\footnotetext{
${ }^{24}$ We performed a Hausman test of the difference between the estimates of $\beta$ in models 1 and 2 . The Hausman test statistic is $H=\left(\beta_{2}-\beta_{1}\right)^{2} /\left(\operatorname{var}\left(\beta_{2}\right)-\operatorname{var}\left(\beta_{1}\right)\right)$, where $\beta_{\mathrm{i}}$ is the estimate of $\beta$ in model $i(i=1,2)$. (See, for example, http://en.wikipedia.org/wiki/Hausman_test) $\mathrm{H}$ follows a $\chi^{2}$ distribution with one degree of freedom. $\mathrm{H}=(.0058$ $.0056)^{2} /\left((.0018)^{2}-(.0016)^{2}\right)=0.059$. The 0.95 critical value of the $\chi^{2}$ distribution with 1 degree of freedom is 3.841 .
} 
other two measures (based on the discrete ingredient vintage measures rx_post1975\% and rx_post1985\%), the remainder of our analysis will be based on the rx_year measure of drug vintage.

The models of survival time shown in Tables 7 and 8 did not include two potentially important behavioral risk factors_-BMI and smoking — as covariates because, as discussed earlier, data on whether or not the individual currently smokes began in 2000, and data on body mass index began in 2001. However, we can assess whether controlling for these variables affects our estimates of the effect of pharmaceutical innovation on survival by estimating a model of an alternative measure of survival - the 3-year survival rate-using data on people interviewed in 2001 and 2002. Table 9 shows estimates of four probit models of the 3-year survival rate. The first 3 models (models 6, 7, and 8) in Table 9 are analogous to models 1-3 in Table 7: model 6 includes the same explanatory variables as model 1, model 7 includes the same explanatory variables as model 2 , and model 8 includes the same explanatory variables as model 3. The coefficient on rx_year is positive and significant in all three models of the 3-year survival rate, indicating that drug vintage had a positive effect on the 3-year survival rate. Controlling for medical conditions, income, education, and other factors reduces the rx_year coefficient by less than 15\%, and the difference between the estimates of the rx_year coefficient in models 6 and 8 is not significant. ${ }^{25}$ Model 9 includes controls for smoking and BMI. ${ }^{26}$ The coefficient on current_smoker is negative but not significant. The BMI dummy variables are jointly significant (p-value $=0.0003$ ), but, contrary to expectations, they indicate that overweight and obese people had higher survival rates than people with healthy weight. However, controlling for the two behavioral risk factors has virtually no effect on the drug vintage coefficient. ${ }^{27}$

To summarize, when we only controlled for age, sex, and interview year, we estimated that a one-year increase in drug vintage increases life expectancy by $0.56 \%$. Controlling for a much more extensive set of other attributes (the mean year the person started taking his or her

\footnotetext{
${ }^{25}$ The value of the Hausman $\mathrm{H}$ statistic is $\mathrm{H}=(.0082-.0095)^{2} /\left((.0040)^{2}-(.0032)^{2}\right)=0.29$.

${ }^{26} 11.1 \%$ of respondents were current smokers. The BMI distribution is: underweight (BMI < 19) $4.1 \%$; healthy weight $(19 \leq \mathrm{BMI}<25) 34.9 \%$; overweight $(25 \leq \mathrm{BMI}<30) 36.4 \%$; obese $(30 \leq \mathrm{BMI}) 24.7 \%$.

${ }^{27}$ We also estimated models of the probability of surviving at least 6 years using the sample of people 65 years and older who were interviewed during 1996-2000. In a specification including the same covariates as model 6 , the estimate of the rx_year coefficient $(\beta)$ was .0059 (s.e. $=.0019$, p-value $=.0017$ ). In a specification including the same covariates as model 7 , the estimate of $\beta$ was .0074 (s.e. $=.0021$, p-value $=.0005$ ). In a specification including the same covariates as model 8 , the estimate of $\beta$ was .0067 (s.e. $=.0021$, p-value $=.0018$ ). The differences between these estimates of $\beta$ were not statistically significant.
} 
medications, and dummy variables for activity limitations, race, education, family income as a percent of the poverty line, insurance coverage, marital status, Census region, BMI, smoking and over 100 medical condition dummy variables) reduced the estimate of $\beta$ by a small amount, to $0.52 \%$.

As shown in Table 3, between 1996 and 2003, the mean value of rx_year increased by 6.6 years, from 1975.9 to 1982.5 . The estimate of $\beta$ (.0052) from model 3 in Table 7 implies that the 1996-2003 increase in mean vintage increased life expectancy of elderly community residents by $3.4 \%(=.0052 * 6.6)$. Sample mean life expectancy (survival time) computed from the right-censored surv_time observations is 13.7 years, so this implies that the 1996-2003 increase in mean vintage increased life expectancy of elderly community residents by 0.47 years (= 3.4\% * 13.7 years). However sample mean life expectancy based on the 1999-2001 CDC life table is about $15 \%$ lower (11.9 years); this estimate of mean life expectancy implies that the 1996-2003 increase in mean vintage increased life expectancy of elderly community residents by 0.41 years $(=3.4 \% * 11.9$ years $)$. According to CDC life tables, life expectancy at age 75 (approximately the mean age of our sample) increased from 11.1 years in 1996 to 11.7 years in 2003, so so the more conservative estimate implies that $68 \%$ of the 0.6 -year increase in the life expectancy of elderly Americans during 1996-2003 was due to the increase in drug vintage.

Since new drugs tend to be more expensive than old drugs, the increase in drug vintage is likely to have increased pharmaceutical expenditure, and may have increased total medical expenditure as well. As indicated in Figure 1, we can assess the impact of pharmaceutical innovation on medical expenditure by estimating models similar to eq. (1), in which the dependent variable is a measure of medical expenditure rather than a survival measure. We estimated models similar to models 1-3 in Table 7, in which the dependent variable was either $\ln \left(\right.$ rx_expend $\left._{\mathrm{i}}\right)$ or $\ln \left(\right.$ tot_expend $\left._{\mathrm{i}}\right)$, where

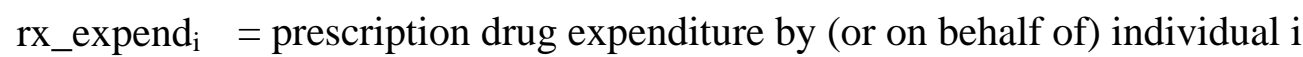
tot_expend ${ }_{i}=$ total medical expenditure by (or on behalf of) individual i

The estimated coefficients on rx_year in these models are shown in Table 10. In models 10-12, the dependent variable is $\ln \left(\mathrm{rx}_{\mathrm{X}}\right.$ expend $\left.\mathrm{d}_{\mathrm{i}}\right)$. When we only control for age, sex, and year (in model 10), the coefficient on rx_year is .034 (p-value <.0001), indicating that a 1year increase in mean drug vintage is associated with a 3.4\% increase in prescription drug expenditure. The rx_year coefficient is about $10 \%$ smaller in models 11 and 12, where we 
control for other covariates. In models 13-15, the dependent variable is $\ln \left(\right.$ tot_expend $\left.\mathrm{d}_{\mathrm{i}}\right)$. When we only control for age, sex, and year (in model 13), the coefficient on rx_year is .0075 (p-value $<.0001$ ), indicating that a 1-year increase in mean drug vintage is associated with a $0.8 \%$ increase in total medical expenditure. The rx_year coefficient is about $40 \%$ smaller when we control (in model 14) for all of the covariates except for activity limitations, and 30\% smaller (in model 15) when we also control for activity limitations. The estimates of models 12 and 15 imply that a 1-year increase in drug vintage increases pharmaceutical expenditure by 3.1\%, and total medical expenditure by $0.53 \%$. The sample mean values of rx_expend and tot_expend were \$1014 and \$6291, respectively. Therefore, the 6.6-year increase in drug vintage that occurred between 1996 and 2003 is estimated to have increased annual drug expenditure per elderly American by $\$ 207$ (= $6.6 * 3.1 \% * \$ 1014)$, and annual total medical expenditure per elderly American by $\$ 218$ (= $6.6 * 0.53 \% * \$ 6291)$.

We can use these estimates to calculate the incremental cost-effectiveness ratio (ICER) of pharmaceutical innovation, defined as follows: ${ }^{28}$

ICER $=\underline{\Delta \text { lifetime medical expenditure }}=\Delta$ lifetime medical expenditure $/ \Delta$ rx_year

$\Delta$ life expectancy

$\Delta$ life expectancy / $\Delta$ rx_year

The effect of the 1996-2003 increase in drug vintage on (undiscounted) lifetime medical expenditure is calculated in the Table 11. The ICER calculation in panel A of Table 11 is based on the mean survival time computed from the right-censored surv_time observations (13.7 years). The use of newer drugs is estimated to have increased lifetime medical expenditure by $\$ 6046$, and life expectancy by 0.47 years. Therefore the ICER (cost per life-year gained) is estimated to be $\$ 12,863$ (= \$6046/ 0.47). ${ }^{29}$ The ICER calculation in panel B of Table 11 is based on sample mean life expectancy computed using the 1999-2001 CDC life table (11.9 years). In this case, the use of newer drugs is estimated to have increased lifetime medical expenditure by

\footnotetext{
${ }^{28}$ This method of calculating the ICER of new drugs is similar to (albeit simpler than) the method used by Duggan and Evans (2008) to simulate the impact of a specific drug (Epivir/PI) on long-term health care spending in the Medicaid program. They recognized that there are two factors that diverge when calculating these costs. First, their results indicated that average annual spending declined when these treatments were introduced. In contrast, the large reduction in mortality generated by Epivir/PI use increased life expectancy, and hence the amount of time that individuals were eligible for Medicaid. They built an illustrative model that allowed them to capture these two opposing factors in a simple calculation.

${ }^{29}$ If we simulate the effect of a 1-year increase in drug vintage, rather than a 6.6-year increase in drug vintage, the calculated ICER is slightly lower: $\$ 12,679$.
} 
\$5263, and life expectancy by 0.41 years. Therefore the ICER (cost per life-year gained) is estimated to be $\$ 12,836$ (= $\$ 5263 / 0.41)$.

Several previous studies have provided estimates of the longevity impact and cost effectiveness of pharmaceutical innovation. The methodologies used in these studies were very different from the methodology used in this paper: previous studies were all based on aggregate data rather than patient-level data, and were based on the entire populations of several countries, not just elderly Americans. Estimates from this and previous studies of the marginal longevity effect (d LE / d rx_year) and the ICER of pharmaceutical innovation are compared in Table 12. In this paper we have estimated that the marginal longevity effect of pharmaceutical innovation is in the 0.062-0.071 range (i.e., a one-year increase in drug vintage increases life expectancy by 0.062-0.071 years), and that the ICER is in the \$12,836-\$12,863 range. Lichtenberg and Duflos (2008) estimated the effect of drug vintage on the mean age at death of Australians using longitudinal disease-level data during the period 1995-2003. Their estimate of the marginal longevity effect was 0.182 , and their estimate of the ICER was \$10,585. Lichtenberg (2011) estimated the effect of drug vintage on life expectancy at birth using longitudinal U.S. state-level data during the period 1991-2004. In that study, the estimate of the marginal longevity effect was 0.135, and the implied estimate of the ICER was $\$ 3645 .^{30}$ Lichtenberg (2012) estimated the effect of drug vintage on life expectancy at birth using longitudinal German state-level data during the period 2001-2007. In that study, the estimate of the marginal longevity effect was 0.208 , and the implied estimate of the ICER was $\$ 16,173 .^{31}$

The mean of the estimates of the marginal longevity effect of pharmaceutical innovation from the three previous studies is about 2.6 times as large as the estimate from this study. However, the longevity measures used in those studies (life expectancy at birth ${ }^{32}$ or mean age at death) were quite different from the one used here (time till death of a population whose mean age is about 75). The mean of the estimates of the ICER of pharmaceutical innovation from the three previous studies is fairly similar to (23\% lower than) the estimate from this study.

\footnotetext{
${ }^{30}$ The growth in per capita medical expenditure was uncorrelated across states with the growth in drug vintage. Therefore, eq. (3) implies that the ICER of pharmaceutical innovation is equal to per capita medical expenditure, which was about \$3645 in the population studied in Lichtenberg (2011).

${ }^{31}$ Lichtenberg and Duflos (2008) and Lichtenberg (2012) did not actually examine the correlation between drug vintage and medical expenditure. Instead, they simply assumed that observed growth in per capita drug expenditure was entirely due to pharmaceutical innovation, and that pharmaceutical innovation had no impact on non-drug medical expenditure.

${ }^{32}$ Life expectancy at birth is based on the survival rates of all age groups.
} 
The four estimates of the ICER of pharmaceutical innovation are reasonably consistent with evidence from clinical trials as reported in the CEA Registry ${ }^{33}$, a comprehensive database of cost-utility analyses on a wide variety of diseases and treatments. A search of the registry found (1) 545 pharmaceutical interventions that decreased cost and improved health (in which case the ICER is negative); (2) 771 pharmaceutical interventions that increased cost and improved health at a cost of less than $\$ 16,173$ per QALY; and (3) 1481 pharmaceutical interventions that increased cost and improved health at a cost of more than \$16,173 per QALY. Therefore, our estimate of the ICER is not very far from the median of the estimates reported in the CEA Registry.

\section{Summary}

This study used patient-level data to analyze the effect of technological change embodied in pharmaceuticals on the longevity of elderly Americans. Previous patient-level studies could not control for important patient attributes such as education, income, and race; they did not provide estimates of the effect of using newer drugs on life expectancy, or of the overall costeffectiveness of new drugs relative to old drugs; and they were not based on nationally representative samples of individuals. Our data, primarily derived from the Medical Expenditure Panel Survey and the Linked Mortality Public-use Files, enabled us to overcome those limitations.

We investigated the effect of the vintage (year of FDA approval) of the prescription drugs used by an individual on his or her survival and medical expenditure, controlling for a number of demographic characteristics and indicators and determinants of health status. When we only controlled for age, sex, and interview year, we estimated that a one-year increase in drug vintage increases life expectancy by $0.52 \%$. Controlling for a much more extensive set of other attributes (the mean year the person started taking his or her medications, and dummy variables for activity limitations, race, education, family income as a percent of the poverty line, insurance coverage, Census region, BMI, smoking and over 100 medical conditions) had virtually no effect on the estimate of the effect of drug vintage on life expectancy.

\footnotetext{
${ }^{33}$ The CEA Registry (https://research.tufts-nemc.org/cear4/) is produced by the Center for the Evaluation of Value and Risk in Health, part of the Institute for Clinical Research and Health Policy Studies at Tufts Medical Center in Boston, MA.
} 
Between 1996 and 2003, the mean vintage of prescription drugs increased by 6.6 years. This is estimated to have increased life expectancy by $0.41-0.47$ years. This suggests that not less than two-thirds of the 0.6-year increase in the life expectancy of elderly Americans during 1996-2003 was due to the increase in drug vintage. The 1996-2003 increase in drug vintage is also estimated to have increased annual drug expenditure per elderly American by \$207, and annual total medical expenditure per elderly American by $\$ 218$. This implies that the incremental cost-effectiveness ratio (cost per life-year gained) of pharmaceutical innovation was about $\$ 12,900$. This estimate of the cost per life-year gained from the use of newer drugs is a small fraction of leading economists' estimates of the value of (willingness to pay for) an additional year of life. It is also consistent with estimates from clinical trials.

\section{References}

Almond, Douglas, and Bhashkar Mazumder (2006), "How did schooling laws improve long-term health and lower mortality?,” Federal Reserve Bank of Chicago Working Paper No WP-06-23, http://www.chicagofed.org/publications/workingpapers/wp2006_23.pdf

Arias E, Curtin LR, Wei R, Anderson RN (2008), “United States decennial life tables for 19992001,” United States life tables. National vital statistics reports; vol 57 no 1. Hyattsville, MD: National Center for Health Statistics, http://www.cdc.gov/nchs/data/nvsr/nvsr57/nvsr57_01.pdf

Bresnahan, Timothy F., and Robert J. Gordon (1996), The Economics of New Goods (Chicago: University of Chicago Press).

CDC (2005), “Annual Smoking-Attributable Mortality, Years of Potential Life Lost, and Productivity Losses --- United States, 1997_2001,” Morbidity and Mortality Weekly Report 54(25);625-628, July 1, http://www.cdc.gov/mmwr/preview/mmwrhtml/mm5425a1.htm

Davis, Peter, and Barry Gribben (1995), "Rational Prescribing and Interpractitioner Variation: A Multilevel Approach,” International Journal of Technology Assessment in Health Care 11, pp 428-442.

de Jong JD, Groenewegen PP, Spreeuwenberg P, Westert GP, de Bakker DH (2009), “Do decision support systems influence variation in prescription?,” BMC Health Serv Res. Jan 30; 9:20.

De Las Cuevas C, Sanz EJ, De La Fuente JA (2002), "Variations in antidepressant prescribing practice: clinical need or market influences?,” Pharmacoepidemiol Drug Saf. 2002 Sep;11(6): 515-22. http://www.ncbi.nlm.nih.gov/pubmed/12426937 
DeSalvo, Karen, Bruce E. Bowdish, Alys S. Alper, David M. Grossman, William W. Merrill (2000), "Physician Practice Variation in Assignment of Return Interval," Arch Intern Med. 160:205-208. http://archinte.ama-assn.org/cgi/content/abstract/160/2/205

Duggan MG, Evans WN (2008), "Estimating the Impact of Medical Innovation: A Case Study of HIV Antiretroviral Treatments,” Forum for Health Economics \& Policy. Volume 11, Issue 2, January.

Flegal, Katherine M., et al (2005), "Excess Deaths Associated with Underweight, Overweight, and Obesity,” JAMA 293:1861-1867, http://jama.ama-assn.org/cgi/content/full/293/15/1861

Hercowitz, Zvi (1998), “The 'embodiment' controversy: A review essay”, Journal of Monetary Economics 41, 217-224.

Krein, Sarah L, Timothy P Hofer, Eve A Kerr, and Rodney A Hayward (2002), "Whom Should We Profile? Examining Diabetes Care Practice Variation among Primary Care Providers, Provider Groups, and Health Care Facilities,” Health Serv Res. 37(5), October: 1159-1180. http://www.ncbi.nlm.nih.gov/pmc/articles/PMC1464024/

Lee, Stephanie J., Steven Joffe, Andrew S. Artz, Richard E. Champlin, Stella M. Davies, Madan Jagasia, Nancy A. Kernan, Fausto R. Loberiza, Jr, Robert J. Soiffer, Mary Eapen (2008), "Individual Physician Practice Variation in Hematopoietic Cell Transplantation,” Journal of Clinical Oncology, Vol 26, No 13 (May 1), 2008: pp. 2162-2170, http://jco.ascopubs.org/content/26/13/2162.full

Lleras-Muney, A. (2005), "The relationship between education and adult mortality in the United States,” Review of Economic Studies 72 (1), 189-221.

Lichtenberg, Frank R. (2010),“The effect of drug vintage on survival: Micro evidence from Puerto Rico's Medicaid program,” in M. Grossman, B. Lindgren, R. Kaestner, and Kristian (eds.), Pharmaceutical Markets and Insurance Worldwide (Advances in Health Economics and Health Services Research, Volume 22), Emerald Group Publishing Limited, pp. 273-292.

Lichtenberg, Frank R. (2011), “The quality of medical care, behavioral risk factors, and longevity growth,” International Journal of Health Care Finance and Economics 11(1), March 2011, 1-34.

Lichtenberg, Frank R. (2012), “The contribution of pharmaceutical innovation to longevity growth in Germany and France, 2001-2007,” PharmacoEconomics 30(3), March 2012, 197-211.

Lichtenberg, Frank, and Gautier Duflos (2008), "Pharmaceutical innovation and the longevity of Australians: a first look,” with Gautier Duflos, Advances in Health Economics and Health Services Research 19, 2008, pp 95-117. 
Lichtenberg, Frank R., Paul Grootendorst, Marc Van Audenrode, Dominick Latremouille-Viau, and Patrick Lefebvre (2009), “The impact of drug vintage on patient survival: a patient-level analysis using Quebec’s provincial health plan data,” Value in Health 12 (6), 847-856.

Meara, Ellen R., Seth Richards, and David M. Cutler (2008), “The Gap Gets Bigger: Changes In Mortality and Life Expectancy, By Education, 1981-2000,” Health Affairs, March/April, 350360.

Murphy, Kevin M. and Topel, Robert H. (2006), “The Value of Health and Longevity,” Journal of Political Economy 114 (4), August, 871-904.

National Science Foundation, U.S. Corporate R\&D: Volume 1: Top 500 Firms in R\&D by Industry Category, http://www.nsf.gov/statistics/nsf00301/expendit.htm.

Nordhaus, William D. (2003), "The Health of Nations: The Contribution of Improved Health to Living Standards," in Measuring the Gains from Medical Research: An Economic Approach, ed. K. M. Murphy and R. H. Topel (Chicago: University of Chicago Press), 9-40.

Rochon PA, Stukel TA, Bronskill SE, Gomes T, Sykora K, Wodchis WP, Hillmer M, Kopp A, Gurwitz JH, Anderson GM (2007), "Variation in nursing home antipsychotic prescribing rates," Arch Intern Med. 167(7):676-83, Apr 9. http://www.ncbi.nlm.nih.gov/pubmed/17420426

Romer, Paul (1990), "Endogenous Technological Change," Journal of Political Economy 98 (5, Part 2), October S71-S102.

Solomon DH, Schneeweiss S, Glynn RJ, Levin R, Avorn J (2003). “Determinants of selective cyclooxygenase-2 inhibitor prescribing: are patient or physician characteristics more important?,” Am J Med. 115(9):715-20, Dec 15. http://www.ncbi.nlm.nih.gov/pubmed/14693324

Wennberg, John (2004), "Practice Variations and Health Care Reform: Connecting the Dots," Health Affairs, October 7, http://www.pnhp.org/news/2004/october/practice_variations_php

Wennberg, John, and David Wennberg, "Practice Variations and the Use of Prescription Drugs," in Dartmouth Atlas of Health Care in Michigan, http://www.bcbsm.com/atlas/profile.shtml

Zink A, Listing J, Ziemer S, Zeidler H (2001), "Practice variation in the treatment of rheumatoid arthritis among German rheumatologists,” J Rheumatol. (10), Oct;28: 2201-8. 
Figure 1

General approach

\section{Rx vintage:}

- Mean FDA approval year of Rx active ingredients

- Fraction of prescriptions that are for "new" drugs

\section{Other individual attributes:}

- interview year

- age

- sex

- race

- marital status

- Census region

- insurance coverage

- education

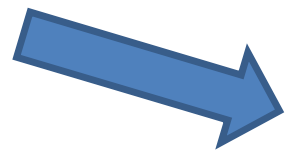

- $\quad$ income (poverty group category)

- presence of $100+$ medical conditions

- how long person has taken medications

- activity limitations

- BMI

- tobacco use

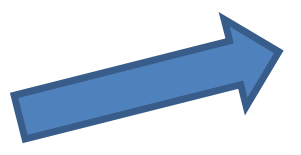

\section{Survival:}

- Number of years till death (right-censored)

- Whether or not person survived a given time period (e.g. 3 years)

\section{Medical expenditure:}

- Prescription drug expenditure

- Total medical expenditure 
Figure 2

Pharmaceutical research expenditure and new pharmaceuticals approved by the FDA, 1995-2010

\section{Fewer New Drugs}

Large drug makers have begun to reduce spending on research and development, while the industry's output of new drugs approved by the Food and Drug Administration remains in decline.
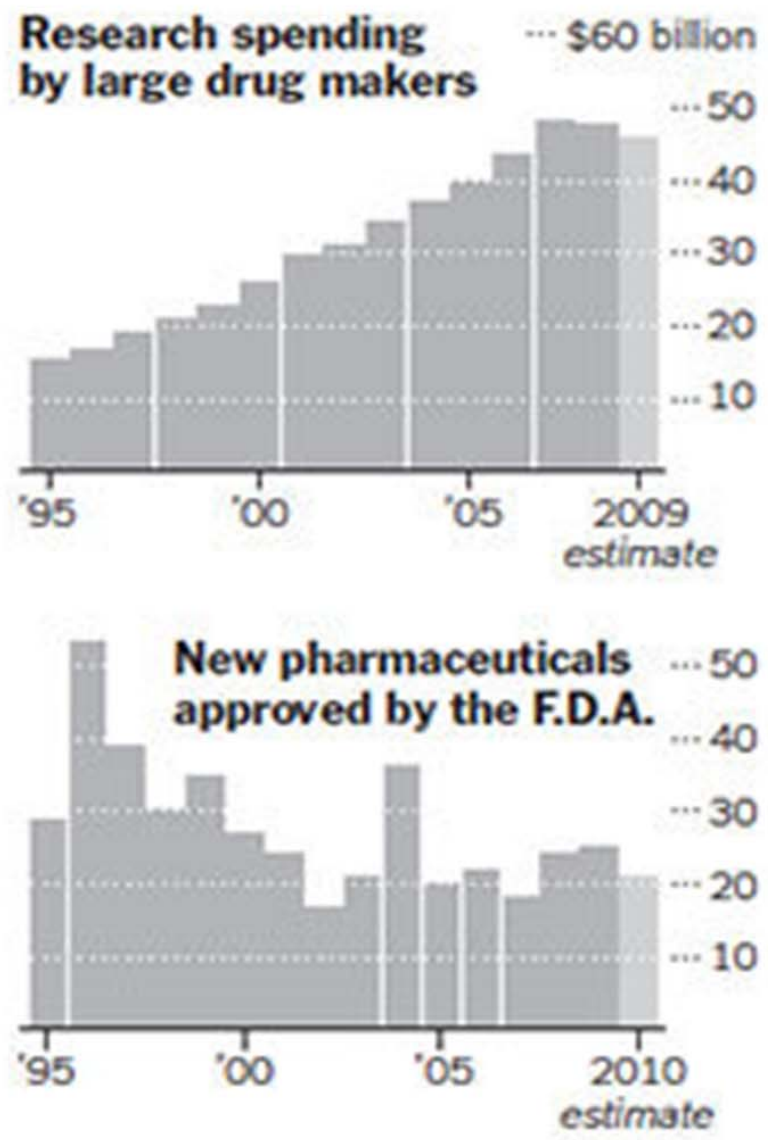

Sources: Pharmaceutical Research and Manufacturers of America; F.DA.

no.NE.W ropx nus 
Table 1

Statistics based on sample of people age 65 and over interviewed in the MEPS during 1996-2000 who were eligible for mortality follow-up and who had at least one prescription drug during the interview year ${ }^{2}$

\begin{tabular}{|l|c|c|c|}
\hline Sex & Number of observations & Mean age & $\begin{array}{c}\text { Mean life expectancy based on 1999- } \\
\text { 2001 CDC life table }\end{array}$ \\
\hline Both sexes & 5230 & 74.3 & 11.9 \\
\hline Male & 2084 & 73.6 & 11.0 \\
\hline Female & 3146 & 74.8 & 12.5 \\
\hline
\end{tabular}

Notes:

[1] Less than half of MEPS respondents were eligible for mortality follow-up. See

http://www.cdc.gov/nchs/data/datalinkage/nhis_frequency_of_selected_variables_public_2010.pdf.

[2] In 2000, 88\% of elderly MEPS respondents had at least one prescription drug during the year.

[3] http://www.cdc.gov/nchs/data/nvsr/nvsr57/nvsr57_01.pdf 
Table 2

Estimates of Weibull shape and scale parameters ( $k$ and $\lambda)$ and of mean survival time

\begin{tabular}{|l|c|c|c|}
\hline Sex & $\lambda$ & $\mathrm{k}$ & Mean survival time $(\lambda \Gamma(1+(1 / \mathrm{k})))$ \\
\hline Both sexes & 14.7 & 1.2 & 13.7 \\
\hline Male & 13.6 & 1.2 & 12.8 \\
\hline Female & 15.4 & 1.3 & 14.3 \\
\hline
\end{tabular}


Table 3

Vintage of prescription drugs used by elderly MEPS respondents, 1996-2008

\begin{tabular}{|c|c|c|c|c|}
\hline year & Number of prescriptions & rx_year & rx_post1975\% & rx_post1985\% \\
\hline 1996 & 38,902 & 1975.9 & $57 \%$ & $26 \%$ \\
\hline 1997 & 64,220 & 1976.4 & $58 \%$ & $30 \%$ \\
\hline 1998 & 46,019 & 1977.2 & $60 \%$ & $34 \%$ \\
\hline 1999 & 45,691 & 1978.5 & $63 \%$ & $38 \%$ \\
\hline 2000 & 47,828 & 1979.5 & $65 \%$ & $42 \%$ \\
\hline 2001 & 68,829 & 1980.6 & $67 \%$ & $46 \%$ \\
\hline 2002 & 82,460 & 1981.6 & $69 \%$ & $49 \%$ \\
\hline 2003 & 69,150 & 1982.5 & $71 \%$ & $52 \%$ \\
\hline 2004 & 81,502 & 1982.4 & $70 \%$ & $52 \%$ \\
\hline 2005 & 92,149 & 1983.2 & $73 \%$ & $54 \%$ \\
\hline 2006 & 106,273 & 1983.5 & $74 \%$ & $54 \%$ \\
\hline 2007 & 89,989 & 1983.9 & $74 \%$ & $56 \%$ \\
\hline 2008 & 82,851 & 1983.9 & $75 \%$ & $57 \%$ \\
\hline \multicolumn{2}{|c|}{ change, 1996-2003 } & 6.6 & $14 \%$ & $26 \%$ \\
\hline
\end{tabular}


Table 4

Percentiles of drug vintage distribution of elderly MEPS respondents, 1996-1999

\begin{tabular}{|l|c|}
\hline Percentile of drug vintage distribution & Value \\
\hline $5 \%$ & 1959.0 \\
\hline $10 \%$ & 1963.6 \\
\hline $25 \%$ & 1970.7 \\
\hline $50 \%$ & 1977.0 \\
\hline $75 \%$ & 1983.0 \\
\hline $90 \%$ & 1988.4 \\
\hline $95 \%$ & 1991.1 \\
\hline
\end{tabular}

$\mathrm{N}=\mathbf{5 2 3 0}$ 
Table 5

Frequencies of individual characteristics

\begin{tabular}{|c|c|}
\hline \multicolumn{2}{|l|}{ Age } \\
\hline$\overline{65-69}$ & $28.4 \%$ \\
\hline $70-74$ & $27.0 \%$ \\
\hline $75-79$ & $21.5 \%$ \\
\hline $80-84$ & $14.0 \%$ \\
\hline $85-89$ & $6.7 \%$ \\
\hline $90+$ & $2.5 \%$ \\
\hline \multicolumn{2}{|l|}{ Interview year } \\
\hline 1996 & $31.7 \%$ \\
\hline 1997 & $19.2 \%$ \\
\hline 1998 & $15.4 \%$ \\
\hline 1999 & $18.7 \%$ \\
\hline 2000 & $15.0 \%$ \\
\hline \multicolumn{2}{|l|}{ Race } \\
\hline$\overline{\text { WHITE }}$ & $85.6 \%$ \\
\hline BLACK & $12.5 \%$ \\
\hline ASIAN OR PACIFIC ISLANDER & $1.4 \%$ \\
\hline AMERICAN INDIAN & $0.5 \%$ \\
\hline ALEUT, ESKIMO & $0.0 \%$ \\
\hline \multicolumn{2}{|c|}{ Family income as $\%$ of poverty line } \\
\hline POOR/NEGATIVE & $16.0 \%$ \\
\hline NEAR POOR & $7.4 \%$ \\
\hline LOW INCOME & $19.8 \%$ \\
\hline MIDDLE INCOME & $28.1 \%$ \\
\hline HIGH INCOME & $28.7 \%$ \\
\hline \multicolumn{2}{|l|}{ Activity limitation } \\
\hline able to do activity & $75.6 \%$ \\
\hline somewhat unable to do activity & $9.1 \%$ \\
\hline completely unable to do activity & $15.3 \%$ \\
\hline
\end{tabular}

Insurance coverage

ANY PRIVATE $\quad 57.7 \%$

PUBLIC ONLY $\quad 42.1 \%$

UNINSURED $\quad 0.2 \%$

Education

ELEMENTARY GRADES 1 - $8 \quad 24.7 \%$

HIGH SCHOOL GRADES 9 - $11 \quad 17.5 \%$

GRADE $12 \quad 30.8 \%$

$1-3$ YEARS COLLEGE $\quad 13.6 \%$

4 YEARS COLLEGE $\quad 7.7 \%$

$5+$ YEARS COLLEGE $\quad 5.6 \%$

Marital status

MARRIED IN ROUND $\quad 53.5 \%$

WIDOWED IN ROUND $\quad 34.6 \%$

DIVORCED $\quad 5.3 \%$

NEVER MARRIED $\quad 3.9 \%$

DIVORCED IN ROUND $\quad 1.5 \%$

SEPARATED $\quad 0.9 \%$

SEPARATED IN ROUND $\quad 0.4 \%$

Region

NORTHEAST $\quad 20.2 \%$

MIDWEST $22.4 \%$

SOUTH $37.3 \%$

WEST $20.1 \%$

$15.3 \%$ 
Table 6

Estimates of drug vintage model (eq. (2)): rx_vintage $e_{i}=\pi Z_{i}+\varepsilon_{i}$

\section{Type III (marginal) sums of squares for all factors except the medical conditions}

\begin{tabular}{|l|r|r|r|r|r|}
\hline Source & DF & SS & MS & FValue & ProbF \\
\hline year & 4 & 10176.16 & 2544.041 & 28.49705 & $1.74 \mathrm{E}-23$ \\
\hline region & 3 & 3079.03 & 1026.343 & 11.49657 & $1.64 \mathrm{E}-07$ \\
\hline SEX & 1 & 1121.655 & 1121.655 & 12.56421 & 0.000396 \\
\hline educyr & 5 & 1137.461 & 227.4922 & 2.548251 & 0.026038 \\
\hline race2 & 4 & 609.3991 & 152.3498 & 1.706545 & 0.145522 \\
\hline age & 5 & 276.7843 & 55.35686 & 0.620079 & 0.684515 \\
\hline POVCAT & 4 & 146.2116 & 36.55291 & 0.409447 & 0.801976 \\
\hline marry & 6 & 157.6191 & 26.26985 & 0.294261 & 0.939921 \\
\hline inscov & 2 & 7.682661 & 3.84133 & 0.043029 & 0.957884 \\
\hline
\end{tabular}

\section{Selected parameter estimates}

\begin{tabular}{|c|c|c|c|c|}
\hline Parameter & Estimate & StdErr & tValue & Probt \\
\hline 1996 & -3.69891 & 0.3916 & -9.44563 & $4.98 \mathrm{E}-21$ \\
\hline 1997 & -3.57032 & 0.428951 & -8.32338 & $1.05 \mathrm{E}-16$ \\
\hline 1998 & -2.40202 & 0.450419 & -5.33287 & 1E-07 \\
\hline 1999 & -1.51924 & 0.428207 & -3.54791 & 0.000391 \\
\hline 2000 & 0 & & & \\
\hline region MIDWEST & 1.864643 & 0.386697 & 4.821978 & $1.46 \mathrm{E}-06$ \\
\hline $\begin{array}{|ll|}\text { region } & \text { NORTHEAST } \\
\end{array}$ & 2.054372 & 0.397907 & 5.162941 & $2.51 \mathrm{E}-07$ \\
\hline region SOUTH & 1.695443 & 0.353876 & 4.791065 & 1.7E-06 \\
\hline region WEST & 0 & & & \\
\hline Female & -1.07884 & 0.30436 & -3.5446 & 0.000396 \\
\hline Male & 0 & & & \\
\hline \begin{tabular}{|ll} 
educyr & 00 - 08 ELEMENTARY GRADES 1 - 8 \\
\end{tabular} & -0.21074 & 0.616176 & -0.34201 & 0.732359 \\
\hline \begin{tabular}{|ll} 
educyr & $09-11 \mathrm{HIGH}$ SCHOOL GRADES 9 - 11 \\
\end{tabular} & -0.70005 & 0.621605 & -1.1262 & 0.260127 \\
\hline \begin{tabular}{|ll} 
educyr 12 GRADE 12 \\
\end{tabular} & -0.16585 & 0.581327 & -0.28529 & 0.775432 \\
\hline \begin{tabular}{|ll} 
educyr & $13-15$ \\
\end{tabular} & -0.72332 & 0.625526 & -1.15635 & 0.247587 \\
\hline \begin{tabular}{|ll} 
educyr & 164 YEARS COLLEGE
\end{tabular} & 1.040067 & 0.685669 & 1.516866 & 0.129355 \\
\hline \begin{tabular}{|ll} 
educyr & $175+$ YEARS COLLEGE \\
\end{tabular} & 0 & & & \\
\hline
\end{tabular}


Table 7

Estimates of survival model (eq. 1) using right-censored data

\begin{tabular}{|c|c|c|c|c|c|c|c|c|c|c|c|c|c|}
\hline & & \multicolumn{4}{|c|}{ Model 1} & \multicolumn{4}{|c|}{ Model 2} & \multicolumn{4}{|c|}{ Model 3} \\
\hline Parameter & Level1 & Estimate & Std Err & \begin{tabular}{|c|} 
ChiSqu \\
are
\end{tabular} & Pr>Chi & Estimate & Std Err & \begin{tabular}{|c|}
$\begin{array}{c}\text { ChiSqu } \\
\text { are }\end{array}$ \\
\end{tabular} & Pr>Chi & Estimate & Std Err & \begin{tabular}{|c|} 
ChiSqu \\
are
\end{tabular} & Pr>Chi \\
\hline rx_year & & 0.0056 & 0.002 & 11.7 & 0.0006 & 0.0058 & 0.002 & 11.1 & 0.0009 & 0.0052 & 0.002 & 8.7 & 0.0032 \\
\hline age & $65-69$ & 1.6611 & 0.088 & 358.2 & $<.0001$ & 1.4533 & 0.090 & 260.6 & $<.0001$ & 1.3707 & 0.090 & 230.5 & $<.0001$ \\
\hline age & $70-74$ & 1.3590 & 0.084 & 260.8 & $<.0001$ & 1.1911 & 0.086 & 193.8 & $<.0001$ & 1.1032 & 0.086 & 164.3 & $<.0001$ \\
\hline age & $75-79$ & 0.9920 & 0.082 & 146.8 & $<.0001$ & 0.8805 & 0.083 & 113.7 & $<.0001$ & 0.8002 & 0.083 & 92.7 & $<.0001$ \\
\hline age & $80-84$ & 0.6205 & 0.082 & 57.5 & $<.0001$ & 0.5443 & 0.081 & 44.9 & $<.0001$ & 0.4777 & 0.082 & 34.3 & $<.0001$ \\
\hline age & $85-89$ & 0.3889 & 0.088 & 19.5 & $<.0001$ & 0.3735 & 0.087 & 18.5 & $<.0001$ & 0.3093 & 0.087 & 12.6 & 0.0004 \\
\hline age & $90+$ & 0.0000 & & & . & 0.0000 & & & . & 0.0000 & & & \\
\hline SEX & Female & 0.2811 & 0.033 & 72.2 & $<.0001$ & 0.3410 & 0.039 & 78.6 & $<.0001$ & 0.3319 & 0.038 & 75.4 & $<.0001$ \\
\hline SEX & Male & 0.0000 & & & & 0.0000 & & & . & 0.0000 & & & \\
\hline year & 1996 & -0.0952 & 0.058 & 2.7 & 0.098 & -0.1504 & 0.057 & 6.9 & 0.0088 & -0.1281 & 0.057 & 5.0 & 0.025 \\
\hline year & 1997 & -0.1445 & 0.061 & 5.6 & 0.0184 & -0.1141 & 0.060 & 3.6 & 0.0583 & -0.0748 & 0.060 & 1.6 & 0.213 \\
\hline year & 1998 & 0.0430 & 0.067 & 0.4 & 0.52 & 0.0366 & 0.065 & 0.3 & |0.5751 & 0.0571 & 0.065 & 0.8 & 0.3791 \\
\hline year & 1999 & 0.0372 & 0.065 & 0.3 & 0.5686 & 0.0234 & 0.063 & 0.1 & 0.7093 & 0.0389 & 0.063 & 0.4 & 0.535 \\
\hline year & 2000 & 0.0000 & & & & 0.0000 & & & $x$ & 0.0000 & & & \\
\hline act_lim & $\begin{array}{l}0 \text { able to do } \\
\text { activity }\end{array}$ & & & & & & & & & 0.3339 & 0.043 & 61.1 & $<.0001$ \\
\hline act_lim & $\begin{array}{l}1 \text { somewhat } \\
\text { unable }\end{array}$ & & & & & & & & & 0.0878 & 0.056 & 2.5 & 0.114 \\
\hline act_lim & $\begin{array}{l}2 \text { completely } \\
\text { unable }\end{array}$ & & & & & & & & & 0.0000 & & & . \\
\hline began_med_ & year & & & & & -0.0004 & 0.003 & 0.0 & 0.9011 & -0.0002 & 0.003 & 0.0 & 0.9564 \\
\hline race2 & ALEUT, ESKIMO & & & & & 14.5857 & $1 . E+04$ & 0.0 & 0.9992 & 14.4703 & $1 . E+04$ & 0.0 & 0.9992 \\
\hline race2 & AMER. INDIAN & & & & & -0.0118 & 0.206 & 0.0 & 0.9543 & -0.0262 & 0.207 & 0.0 & 0.8992 \\
\hline race2 & ASIAN/PACIFIC & & & & & 0.3896 & 0.170 & 5.3 & 0.0219 & 0.3770 & 0.169 & 5.0 & 0.0256 \\
\hline race2 & BLACK & & & & & -0.0832 & 0.049 & 3.0 & 0.086 & -0.0790 & 0.049 & 2.7 & 0.1034 \\
\hline race2 & WHITE & & & & & 0.0000 & & & . & 0.0000 & & & \\
\hline POVCAT & POOR/NEGATIVE & & & & & -0.0564 & 0.053 & 1.1 & 0.2864 & -0.0292 & 0.053 & 0.3 & 0.5811 \\
\hline POVCAT & NEAR POOR & & & & & -0.1469 & 0.063 & 5.5 & 0.0189 & -0.1402 & 0.062 & 5.1 & 0.0243 \\
\hline POVCAT & LOW INCOME & & & & & -0.0629 & 0.049 & 1.7 & 0.1947 & -0.0530 & 0.048 & 1.2 & 0.273 \\
\hline POVCAT & MIDDLE INCOME & & & & & -0.0012 & 0.045 & 0.0 & 0.9785 & -0.0065 & 0.045 & 0.0 & 0.8847 \\
\hline POVCAT & HIGH INCOME & & & & & 0.0000 & & & . & 0.0000 & & & . \\
\hline inscov & ANY PRIVATE & & & & & -0.8187 & 0.723 & 1.3 & 0.2576 & -0.8491 & 0.720 & 1.4 & 0.2383 \\
\hline inscov & PUBLIC ONLY & & & & & -0.8734 & 0.723 & 1.5 & 0.227 & -0.8823 & 0.720 & 1.5 & 0.2203 \\
\hline inscov & UNINSURED & & & & & 0.0000 & & & . & 0.0000 & & & \\
\hline educyr & $0-8$ years & & & & & -0.2010 & 0.089 & 5.1 & 0.0233 & -0.1585 & 0.088 & 3.2 & 0.0723 \\
\hline educyr & 9-11 years & & & & & -0.2906 & 0.090 & 10.5 & 0.0012 & -0.2554 & 0.089 & 8.2 & 0.0043 \\
\hline educyr & 12 years & & & & & -0.2097 & 0.087 & 5.9 & 0.0153 & -0.1850 & 0.086 & 4.6 & 0.0315 \\
\hline educyr & $13-15$ years & & & & & -0.1421 & 0.092 & 2.4 & 0.1236 & -0.1343 & 0.092 & 2.2 & 0.1429 \\
\hline educyr & 16 years & & & & & -0.1070 & 0.101 & 1.1 & 0.2884 & -0.0952 & 0.100 & 0.9 & 0.3425 \\
\hline educyr & $\begin{array}{l}17 \text { 5+ YEARS } \\
\text { COLLEGE }\end{array}$ & & & & & 0.0000 & & & . & 0.0000 & & & \\
\hline region & MIDWEST & & & & & 0.0371 & 0.049 & 0.6 & 0.4457 & 0.0325 & 0.048 & 0.5 & 0.5017 \\
\hline region & NORTHEAST & & & & & 0.0292 & 0.051 & 0.3 & 0.5655 & 0.0177 & 0.051 & 0.1 & 0.7272 \\
\hline region & SOUTH & & & & & -0.0024 & 0.045 & 0.0 & 0.9579 & 0.0050 & 0.045 & 0.0 & 0.9102 \\
\hline region & WEST & & & & & 0.0000 & & & + & 0.0000 & & & \\
\hline marital statu & Is dummies & no & & & & yes & & & & yes & & & \\
\hline $\begin{array}{l}\text { 100+ medica } \\
\text { dummies }\end{array}$ & condition & no & & & & yes & & & & yes & & & \\
\hline
\end{tabular}


Table 8

Estimates of drug vintage coefficients from models based on alternative measures of drug vintage

\begin{tabular}{|l|l|c|c|c|c|}
\hline Model & rx_vintage measure & Estimate & StdErr & ChiSq & ProbChiSq \\
\hline 3 & rx_year & 0.0052 & 0.002 & 8.71 & 0.003 \\
\hline 4 & rx_post1975\% & 0.177 & 0.050 & 12.40 & 0.000 \\
\hline 5 & rx_post1985\% & 0.112 & 0.056 & 4.00 & 0.045 \\
\hline
\end{tabular}


Table 9

Estimates of probit models of the 3-year survival rate based on data for 2001 and 2002

\begin{tabular}{|c|c|c|c|c|c|c|c|c|c|c|c|c|c|c|c|c|c|}
\hline & & \multicolumn{4}{|c|}{ Model 6} & \multicolumn{4}{|c|}{ Model 7} & \multicolumn{4}{|c|}{ Model 8} & \multicolumn{4}{|c|}{ Model 9} \\
\hline Parameter & Level1 & Estimate & Std Err & \begin{tabular}{|c|} 
ChiSqu \\
are
\end{tabular} & Pr>Chi & \begin{tabular}{|c|} 
Estimat \\
$\mathrm{e}$
\end{tabular} & Std Err & \begin{tabular}{|c|} 
ChiSqu \\
are
\end{tabular} & Pr>Chi & \begin{tabular}{|c|} 
Estimat \\
$\mathrm{e}$
\end{tabular} & Std Err & \begin{tabular}{|c|} 
ChiSqua \\
re
\end{tabular} & Pr>Chi & \begin{tabular}{|c|} 
Estimat \\
$\mathrm{e}$
\end{tabular} & $\begin{array}{l}\text { Std } \\
\text { Err }\end{array}$ & \begin{tabular}{|c|} 
ChiSqu \\
are
\end{tabular} & Pr>Chi \\
\hline rx_year & & 0.0095 & 0.003 & 8.7 & 0.0032 & 0.0091 & 0.004 & 5.54 & 0.0185 & 0.0082 & 0.004 & 4.31 & 0.038 & 0.0083 & 0.004 & 4.33 & 0.0375 \\
\hline age & $65-69$ & 1.250 & 0.114 & 120.9 & $<.0001$ & 1.151 & 0.141 & 66.9 & $<.0001$ & 1.072 & 0.143 & 55.87 & $<.0001$ & 0.997 & 0.148 & 45.63 & $<.0001$ \\
\hline age & $70-74$ & 0.995 & 0.108 & 84.77 & $<.0001$ & 0.934 & 0.132 & 50.06 & $<.0001$ & 0.825 & 0.135 & 37.68 & $<.0001$ & 0.744 & 0.138 & 29.21 & $<.0001$ \\
\hline age & $75-79$ & 0.767 & 0.108 & 50.81 & $<.0001$ & 0.713 & 0.126 & 32.24 & $<.0001$ & 0.642 & 0.127 & 25.49 & $<.0001$ & 0.589 & 0.129 & 20.68 & $<.0001$ \\
\hline age & $80-84$ & 0.500 & 0.113 & 19.7 & $<.0001$ & 0.474 & 0.127 & 14.01 & 0.0002 & 0.421 & 0.128 & 10.84 & 0.001 & 0.392 & 0.130 & 9.15 & 0.0025 \\
\hline age & $85-89$ & 0.000 & & 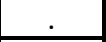 & & 0.000 & 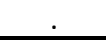 &. &. & 0.000 & & 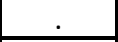 & & 0.000 & & & . \\
\hline SEX & Female & 0.242 & 0.066 & 13.51 & 0.0002 & 0.260 & 0.090 & 8.36 & 0.0038 & 0.281 & 0.092 & 9.41 & 0.0022 & 0.306 & 0.093 & 10.77 & 0.001 \\
\hline SEX & Male & 0.000 & . & . & . & 0.000 & . & . & $\cdot$ & 0.000 & . & . & & 0.000 &. & . & . \\
\hline year & 2001 & 0.014 & 0.066 & 0.04 & 0.8372 & -0.054 & 0.078 & 0.48 & 0.4901 & \begin{tabular}{|l|}
-0.077 \\
\end{tabular} & 0.079 & 0.94 & 0.3333 & -0.083 & 0.080 & 1.07 & 0.3014 \\
\hline year & 2002 & 0.000 & $\dot{-}$ & $\dot{.}$ & $\cdot$ & 0.000 & . & 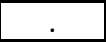 & . & 0.000 & $x_{1}$ & . & & 0.000 &. & . & . \\
\hline began_med & year & & & & & -0.002 & 0.008 & 0.04 & 0.8478 & 0.000 & 0.008 & 0 & 0.9547 & 0.001 & 0.008 & 0.01 & 0.9367 \\
\hline act_lim & 0 able to do activity & & & & & & & & & 0.622 & 0.097 & 40.89 & $<.0001$ & 0.633 & 0.098 & 41.52 & $<.0001$ \\
\hline act_lim & 1 somewhat unable & & & & & & & & & 0.202 & 0.133 & 2.32 & 0.1275 & 0.170 & 0.134 & 1.62 & 0.2036 \\
\hline act_lim & 2 completely unable & & & & & & & & & 0.000 & . & . & . & 0.000 & . & . & . \\
\hline current_smok & ker & & & & & & & & & & & & & -0.071 & 0.121 & 0.34 & 0.557 \\
\hline $\mathrm{bmi}$ & 0 underweight & & & & & & & & & & & & & -0.297 & 0.185 & 2.59 & 0.1078 \\
\hline bmi & 1 healthy weight & & & & & & & & & & & & & -0.301 & 0.104 & 8.32 & 0.0039 \\
\hline $\mathrm{bmi}$ & 2 overweight & & & & & & & & & & & & & 0.068 & 0.107 & 0.41 & 0.5241 \\
\hline $\mathrm{bmi}$ & 3 obese & & & & & & & & & & & & & 0.000 & & 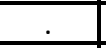 & . \\
\hline race & & no & & & & yes & & & & yes & & & & yes & & & \\
\hline income group & & no & & & & yes & & & & yes & & & & yes & & & \\
\hline insurance cov & verage & no & & & & yes & & & & yes & & & & yes & & & \\
\hline education & & no & & & & yes & & & & yes & & & & yes & & & \\
\hline region & & no & & & & yes & & & & yes & & & & yes & & & \\
\hline marital status & & no & & & & yes & & & & yes & & & & yes & & & \\
\hline $100+$ medical & condition dummies & no & & & & yes & & & & yes & & & & yes & & & \\
\hline
\end{tabular}

The estimates are based on 2805 observations: 2480 people survived; 325 people did not survive 3 years. 
Table 10

Estimates of the effect of drug vintage on prescription drug expenditure and total medical expenditure

\begin{tabular}{|c|c|c|c|c|c|c|}
\hline Model & 10 & 11 & 12 & 13 & 14 & 15 \\
\hline Dependent variable & $\begin{array}{l}\text { log of annual } \\
\text { prescription } \\
\text { drug } \\
\text { expenditure }\end{array}$ & $\begin{array}{c}\text { log of annual } \\
\text { prescription } \\
\text { drug } \\
\text { expenditure }\end{array}$ & $\begin{array}{c}\text { log of annual } \\
\text { prescription } \\
\text { drug } \\
\text { expenditure }\end{array}$ & $\begin{array}{l}\text { log of annual } \\
\text { total medical } \\
\text { expenditure }\end{array}$ & $\begin{array}{l}\text { log of annual } \\
\text { total medical } \\
\text { expenditure }\end{array}$ & $\begin{array}{l}\text { log of annual } \\
\text { total medical } \\
\text { expenditure }\end{array}$ \\
\hline \multicolumn{7}{|l|}{ rx year coefficient } \\
\hline Estimate & 0.0340 & 0.0304 & 0.0309 & 0.0075 & 0.0044 & 0.0053 \\
\hline Standard Error & 0.002 & 0.001 & 0.001 & 0.002 & 0.002 & 0.002 \\
\hline t Value & 19.91 & 20.9 & 21.25 & 4.17 & 2.82 & 3.39 \\
\hline $\operatorname{Pr}>|\mathrm{t}|$ & $<.0001$ & $<.0001$ & $<.0001$ & $<.0001$ & 0.0049 & 0.0007 \\
\hline \multicolumn{7}{|l|}{ covariates } \\
\hline age & yes & yes & yes & yes & yes & yes \\
\hline sex & yes & yes & yes & yes & yes & yes \\
\hline year & yes & yes & yes & yes & yes & yes \\
\hline began_med_year & no & yes & yes & yes & yes & yes \\
\hline race & no & yes & yes & yes & yes & yes \\
\hline income group & no & yes & yes & yes & yes & yes \\
\hline insurance coverage & no & yes & yes & yes & yes & yes \\
\hline education & no & yes & yes & yes & yes & yes \\
\hline region & no & yes & yes & yes & yes & yes \\
\hline marital status & no & yes & yes & yes & yes & yes \\
\hline $\begin{array}{l}\text { 100+ medical condition } \\
\text { dummies }\end{array}$ & no & yes & yes & yes & yes & yes \\
\hline act_lim & no & no & yes & no & no & yes \\
\hline
\end{tabular}

Mean annual prescription drug expenditure $=\$ 1014$

Mean annual total medical expenditure $=\$ 6291$ 


\section{Table 11}

Calculation of the incremental cost-effectiveness ratio (ICER) of pharmaceutical innovation

A. Baseline life expectancy computed from right-censored surv_time observations

\begin{tabular}{|l|c|c|c|}
\hline & $\begin{array}{c}\text { Life } \\
\text { expectancy (1) }\end{array}$ & $\begin{array}{c}\text { Annual medical } \\
\text { expenditure (2) }\end{array}$ & $\begin{array}{c}\text { Lifetime medical } \\
\text { expenditure (1) * (2) }\end{array}$ \\
\hline Baseline & 13.70 & $\$ 6,291$ & $\$ 86,187$ \\
\hline Baseline + effect of 6.6-year increase in drug vintage & 14.17 & $\$ 6,509$ & $\$ 92,233$ \\
\hline Effect of 6.6-year increase in drug vintage & 0.47 & $\$ 218$ & $\$ 6,046$ \\
\hline
\end{tabular}

B. Baseline life expectancy based on 1999-2001 CDC life table

\begin{tabular}{|l|c|c|c|}
\hline & $\begin{array}{c}\text { Life } \\
\text { expectancy (1) }\end{array}$ & $\begin{array}{c}\text { Annual medical } \\
\text { expenditure (2) }\end{array}$ & $\begin{array}{c}\text { Lifetime medical } \\
\text { expenditure (1) * (2) }\end{array}$ \\
\hline Baseline & 11.90 & $\$ 6,291$ & $\$ 74,863$ \\
\hline Baseline + effect of 6.6-year increase in drug vintage & 12.31 & $\$ 6,509$ & $\$ 80,126$ \\
\hline Effect of 6.6-year increase in drug vintage & 0.41 & $\$ 218$ & $\$ 5,263$ \\
\hline
\end{tabular}


Table 12

Comparison of estimates to those from three previous studies

\begin{tabular}{|c|c|c|c|c|c|c|c|}
\hline Study & Age group & Country & Period & Longevity measure & Methodology & $\Delta$ LE / $\Delta$ RX_YEAR & ICER \\
\hline & $\begin{array}{l}\text { Elderly (65+) } \\
\text { community } \\
\text { residents }\end{array}$ & USA & $1996-2000$ & Time till death & $\begin{array}{l}\text { patient-level } \\
\text { cross-section }\end{array}$ & $.062-.071$ & $\$ 12,836-\$ 12,863$ \\
\hline \multicolumn{8}{|c|}{ Previous studies } \\
\hline $\begin{array}{l}\text { Lichtenberg } \\
(2011)\end{array}$ & Entire population & USA & 1991-2004 & $\begin{array}{l}\text { Life expectancy at } \\
\text { birth }\end{array}$ & $\begin{array}{l}\text { longitudinal } \\
\text { state-level }\end{array}$ & 0.135 & $\$ 3,645$ \\
\hline $\begin{array}{l}\text { Lichtenberg } \\
(2012)\end{array}$ & Entire population & Germany & 2001-2007 & $\begin{array}{l}\text { Life expectancy at } \\
\text { birth }\end{array}$ & $\begin{array}{l}\text { longitudinal } \\
\text { state-level }\end{array}$ & 0.208 & $\$ 16,173$ \\
\hline
\end{tabular}

